\title{
A medium-term intervention study on the impact of high- and low-fat snacks varying in sweetness and fat content: large shifts in daily fat intake but good compensation for daily energy intake
}

\author{
Clare L. Lawton*, Helen J. Delargy, Fiona C. Smith, Vikki Hamilton and John E. Blundell \\ BioPsychology Group, School of Psychology, University of Leeds, Leeds LS2 9JT, UK
}

(Received 7 November 1997 - Revised 28 January 1998 - Accepted 13 February 1998)

\begin{abstract}
Thirty-six normal-weight, habitual snackers (eighteen males, eighteen females) completed a medium-term intervention study designed to examine the tendency of four different types of snacks, varying in nutrient (low- (LF) or high-fat (HF)) and sensory properties (sweet (SW) or non-sweet (NSW)), to influence the control of appetite and to adjust daily energy intake. Subjects were exposed to each snack category for a 3-week period and were asked to consume a minimum number of snacks each day so that at least $25 \%$ of their daily energy intake would be derived from the test snacks. Energy and macronutrient intakes from the test snacks were calculated every day and also from other eating episodes (using $3 \mathrm{~d}$ food diary records) during the third week of snack exposure. Subjects consumed more energy/d from the SW snacks than from the NSW snacks, with most energy being consumed from the HF/SW snacks $(3213 \mathrm{~kJ})$ and least energy from the LF/NSW snacks $(1628 \mathrm{~kJ})$. This differential snack intake remained stable across the whole snack exposure period. Total daily energy intake did not differ significantly during exposure to any of the four snack types. Furthermore, the encouragement to eat freely from the test snacks did not lead to daily overconsumption of energy when compared with pre-study intakes. Hence, the level of snack consumption was largely compensated for by the energy consumed from the rest of the eating pattern. Although daily energy intake during exposure to the HF snacks was an average of $364 \mathrm{~kJ}$ higher (NS) than that during exposure to the LF snacks, the clearest and most significant effect of snack consumption was on daily macronutrient intake. Appreciable consumption of the HF snacks raised the percentage of total daily energy intake consumed as fat from 37 to $41 \%(P<0 \cdot 01)$. In contrast, the LF snacks reduced daily fat intake to $33.5 \%$ (LF/SW, $P<0.05$; LF/NSW, NS) of total daily energy. The results, therefore, suggest that, in habitual snackers, generous consumption of LF snacks, when compared with HF snacks, is an effective strategy to reduce fat intake so that it approaches the recommendations of dietary guidelines without increasing total daily energy intake.
\end{abstract}

Snacking: Energy intake: Fat intake: Dietary targets: Appetite

Obesity represents one of the major health problems in Western (affluent and technologically developed) societies. In the UK, the Health of the Nation (1992) target is that by the year 2005 the percentage of people aged 16-64 years who are obese will be reduced from the 1986/7 baseline of $8 \%$ men and $12 \%$ women (Gregory et al. 1990, The Dietary and Nutritional Survey of British Adults) to no more than $6 \%$ and $8 \%$ respectively. However, the most recently reported Health Survey for England, carried out in 1995 (Prescott-Clarke et al. 1997), indicated that the situation is deteriorating rather than improving. Hence in 1995, $15 \%$ of men and $18 \%$ of women in the 16-64 year age group were classified as obese. Furthermore, this trend towards increasing obesity in the adult population has also been reported in many other countries, e.g. USA, Australia and Germany (Kuczmarski et al. 1994).

It is now widely accepted that obesity and the overweight condition are attributable to an interaction between diet, lifestyle and genetics (Prentice \& Jebb, 1995; Golay \& Bobbioni, 1997). This has led to a huge interest in identifying features of the diet which could contribute to weight gain. A number of epidemiological studies have indicated a positive relationship between the proportion of fat in the diet and the prevalence of overweight or obesity (e.g. Dreon et al. 1988; Romieu et al. 1988; Tremblay et al. 1989; Millar et al. 1990). Indeed 'there is evidence from several sources to indicate that the consumption of a high-fat diet undermines the normal mechanisms regulating energy balance in 
humans' (Prentice \& Jebb, 1995). The study of Gregory et al. (1990) revealed that average daily fat intake in 1986/7 was $102 \mathrm{~g}$ for men and $73 \mathrm{~g}$ for women and that this amounted to $40 \%$ of total food energy. These amounts are considerably in excess of the $35 \%$ of food energy recommended by the Health of the Nation white paper (1992) and the $30 \%$ of total daily energy intake recommended by nutrition experts in the USA (National Research Council, 1989).

Why do dietary fat intakes remain unacceptably high? We have suggested two possible explanations for this (Blundell et al. 1993). First, people are actively seeking out dietary fat and when offered an opportunity, they actively ingest it, thereby increasing their energy intake (EI). Second, people exposed to a high-fat diet, particularly when hunger is high, display a passive tendency to overconsume energy (probably due to the high palatability and high energy density of high-fat foods). This second explanation is favoured by recent reviews (e.g. Golay \& Bobbioni, 1997). In both cases the excessive EI does not appear to be subjected to any potent inhibitory action from the physiological monitoring of ingested fat.

Although research over the past $10-15$ years has increasingly pointed to fat as the dietary factor most closely associated with weight gain, interest has also been expressed in the role of the amount of sugar or sweet foods in the diet and in the role of pattern of eating or eating frequency. Beliefs that a high intake of sugar promotes weight gain and that increased eating frequency (more usually referred to as snacking between meals) promotes weight gain are widely held, and taken as fact, by much of the lay public. Experimental evidence for both these beliefs is, however, difficult to find.

Although animal studies indicate that both high-sugar and high-fat diets can lead to hyperphagia and weight gain (e.g. Sclafani \& Springer, 1976; Kanarek \& Hirsch, 1977; Blundell \& Hill, 1988), the picture is not so clear with humans. Epidemiological studies show that lean individuals tend to consume more sugar than overweight people (Glinsmann et al. 1986) and that sugar intake is inversely related to fat intake (sugar-fat seesaw, e.g. Gregory et al. 1990). This reciprocal relationship between the percentage of sugar and percentage of fat reported as being consumed is apparent in large-scale surveys (Bolton-Smith \& Woodward, 1994). The highest proportion of obese people are, therefore, found among the cohort of high-fat/low-sugar consumers. Mela \& Rogers (1993) have, however, suggested that obese people might either under-report intake of sweet foods or actively avoid them in an attempt to lose weight. Furthermore, a short-term study conducted by Green et al. (1994) found that normal-weight, young male subjects consumed significantly more energy from a selection of high-fat (low-sucrose) snacks than from a selection of equally palatable high-sucrose (low-fat) snacks. In addition, the increase in EI due to the high-fat foods did not generate a greater suppression of subsequent food intake. Green et al. (1994) conclude that high-fat foods have a weaker effect on satiety and, therefore, a greater potential for permitting overconsumption than high-sucrose foods. This does not, however, rule out the possibility that consumption of foods high in both fat and sugar could pose a risk of overconsumption. Indeed, some authors have implicated the combination of sugar and fat in foods in overconsumption (Drewnowski et al. 1992; Emmett \& Heaton, 1995) and some analyses point to a positive relationship between consumed sugar and fat when the data are expressed in terms of absolute weight of consumed nutrients (Macdiarmid et al. 1995).

With regard to the effects of eating pattern and eating frequency on weight gain, it has been reported that obese individuals eat more often, eat more food in one sitting and derive a larger proportion of their EI from evening meals and snacks than their lean counterparts (Beaudoin \& Mayer, 1953). Similarly, Basdevant et al. (1993) studied snacking patterns in 273 obese women and found that snacking played an important role in increasing energy consumption. Despite these reports, it would seem that there is slightly more justification for the view that infrequent eating leads to higher body weights (e.g. Fabry et al. 1964; Metzner et al. 1977). Indeed, a recent review of the relevant literature (Bellisle et al. 1997) indicates that the relationship between frequency of eating and body weight is consistently inverse in those epidemiological studies that do observe a relationship. The authors go on, however, to show conclusively that the apparent relationship between infrequent eating and obesity can be explained by dietary under-reporting (which invalidates some of the relevant studies) and by the confounding effects of post hoc changes in dietary patterns as a consequence of weight gain (e.g. skipping breakfast in an attempt to lose weight).

Given an increasing recognition of the importance of snacking as a lifestyle feature, and of a continuing shift away from meal-taking towards a grazing type of eating pattern, it is important to understand the effects of different types of snacks on appetite control. Burley et al. (1993) showed that spreading EI over the day into five eating episodes, instead of into three main meals, resulted in a flatter profile of hunger across the day. It has also been demonstrated that when hunger is high, consumption of high-fat foods at a subsequent meal is increased in both lean (Green et al. 1994) and obese subjects (Lawton et al. 1993). Green \& Burley (1996) have therefore suggested that the insertion of snacks between meals (depending on macronutrient composition) may reduce hunger peaks and prevent subsequent overconsumption (at meals). Snacking on appropriate (i.e. low-fat) foods may, therefore, help to prevent the occurrence of a positive energy balance although snacking on inappropriate (i.e. high-fat) foods may have the opposite effect.

The present study was designed to examine the putative tendency of snack consumption to facilitate the development of a positive energy balance in a medium-term intervention study. Subjects were given an ample supply of snacks and encouraged to eat at least $25 \%$ of their daily EI from the snacks for 3-week periods. This strategy was designed to give subjects every opportunity to eat themselves into a positive energy balance and tested the degree of energy compensation which could be exerted to offset snack intake. The study measured the impact of the intervention on total daily energy and nutrient intakes and on various other aspects of appetite control. 


\section{Subjects and methods}

\section{Subjects}

Forty subjects (twenty males and twenty females) were selected from 121 people who responded to either a letter or an advertisement requesting 'snackers' to take part in a study on nutrition and health. Snackers were chosen since the aim of the study was to determine the effect of sensorynutrient properties of snacks in people already displaying the snacking habit, and not to mount a snacking intervention in non-snackers. All subjects were either staff (clerical, technical and junior research) or post-graduate students from the University of Leeds. All were aged 17-44 years, had a BMI $18-30 \mathrm{~kg} / \mathrm{m}^{2}$, and scored less than 13 on the restraint scale of the Three-Factor Eating Questionnaire (Stunkard \& Messick, 1985). They were habitual snackers (69\% reported normally consuming three to four snacks/d) and expressed a liking for all of the snacks to be used in the study (assessed by means of a taste test). None of the subjects were trained athletes, taking any drugs known to affect appetite, pregnant, planning pregnancy, or pregnant in the previous 6-month period. Further subject characteristics are shown in Tables 1 and 2.

Four subjects $(10 \%)$ were unable to complete the $147 \mathrm{~d}$ study and hence data are presented for the thirty-six subjects (eighteen males and eighteen females) who completed all phases of the study.

\section{Experimental design}

The study conformed to a $2 \times 2$ fully repeated-measures design. Each subject was exposed to each of four experimental conditions (snack categories) in a counterbalanced order. There were two levels of sweetness of snacks (sweet (SW) or non-sweet (NSW)) and two levels of nutrient composition of snacks (low-fat (LF) or high-fat (HF)). Hence, the effects of snacks corresponding to the following sensory and nutrient combinations were studied: low-fat/ sweet (LF/SW), high-fat/sweet (HF/SW), low-fat/non-sweet (LF/NSW), high-fat/non-sweet (HF/NSW). Subjects were exposed to each snack category for a period of 3 weeks ( $21 \mathrm{~d}$ : the periods of exposure to the snacks are referred to as experimental phases) with a 3-week 'washout' period between exposure to each snack category. The study was, therefore, designed to examine the effects of different types of snacks, and not to test the effects of snacks $v$. no snacks.

\section{Snack foods}

The energy and nutrient content of the individual snacks and the mean values for each snack category are shown in Table 3. Snacks included in the LF categories derived $\leq 30 \%$ of their energy from fat, those in the HF categories $\geq 50 \%$ energy from fat. In order that the snacks should be comparable, the energy content of each snack unit was as close to $418 \mathrm{~kJ}(100 \mathrm{kcal})$ as possible. The protein content of the snacks in each category was similar. The snacks were either commercially available products or were slightly modified to achieve the target of approximately $418 \mathrm{~kJ}$ and to ensure that the manufacturers would be unidentifiable.

The relative palatability and other characteristics of the snacks were checked by a taste test carried out before the start of the study. Subjects were required to taste a bite-sized portion of each snack food and then rate it (using $100 \mathrm{~mm}$ visual analogue scales) according to (a) how sweet, savoury, tasty and pleasant they found it; (b) how filling and how satisfying they expected it to be; (c) how much more of it they thought they could eat (i.e. prospective consumption). Foods were rated in a counterbalanced order and subjects were required to cleanse their palate between tastings by consuming a small piece of water biscuit and a few sips of water. An average score for the foods in each snack category was calculated for each subject, for each attribute. The mean ( $n$ 36) of the average score of each subject was then calculated for each snack category. The mean scores for

Table 1. Characteristics of subjects ( $n$ 36; eighteen male and eighteen female)

\begin{tabular}{lr}
\hline Characteristic & $\%$ \\
\hline Occupation: & 47 \\
$\quad$ Administrative-type (secretaries, clerks, office supervisors etc.) & 22 \\
Academic/research (PhD students, research assistants) & 28 \\
Technical staff & 3 \\
$\quad$ Managerial & 28 \\
Smoker & 17 \\
Vegetarian & 75 \\
Reported normally eating regular meals & 69 \\
Never tried to lose weight & 92 \\
Weight stable in previous 6 months & 8 \\
Experienced weight changes of $\leq 3 \cdot 2 \mathrm{~kg}$ & \\
Typical weekly alcohol consumption was extremely variable: & \\
Females: 7 units & \\
Males: 15 units & \\
Exercise: & \\
$\quad$ Trained athletes & 61 \\
Took part in at least one exercise activity session per week & \\
\hline
\end{tabular}


Table 2. Pre-study snacking habits ( $n$ 36: eighteen male and eighteen female)

\begin{tabular}{|c|c|}
\hline Snacking habit & $\%$ \\
\hline $\begin{array}{l}\text { Subjects were recruited on the basis that they considered themselves to be } \\
\text { Reported normally eating } 5 \text { or } 6 \text { snacks per day } \\
\text { Reported normally eating } 3 \text { or } 4 \text { snacks per day } \\
\text { Reported normally eating } 1 \text { or } 2 \text { snacks per day }\end{array}$ & $\begin{array}{r}25 \\
69 \\
6\end{array}$ \\
\hline $\begin{array}{l}\text { Time of day that snacking occurred: } \\
\text { Subjects were able to identify times of the day that they were most likely } t\end{array}$ & \\
\hline $\begin{array}{l}\text { Foods most likely to be chosen: } \\
\text { Most commonly mentioned were chocolate bars \& crisps } \\
\text { Also commonly mentioned were biscuits, sandwiches, toast \& fruit }\end{array}$ & \\
\hline $\begin{array}{l}\text { Sweet/savoury preferences: } \\
\text { Reported having a 'sweet tooth' } \\
\text { Reported having a 'savoury tooth' } \\
\text { No preference }\end{array}$ & $\begin{array}{l}50 \\
25 \\
25\end{array}$ \\
\hline $\begin{array}{l}\text { What prompts a snack? } \\
\text { Hunger } \\
\text { To prevent them from getting hungry later } \\
\text { Because they fancied something tasty even though they were not hungry } \\
\text { When they see other people eating } \\
\text { Tiredness } \\
\text { Habit } \\
\text { Having a drink } \\
\text { Boredom } \\
\text { Stress, anxiety or bad-temper (i.e. a negative affect) } \\
\text { Depression } \\
\text { Missing meals } \\
\text { Being about to exercise } \\
\text { Being pre-menstrual } \\
\text { Being happy \& relaxed }\end{array}$ & $\begin{array}{r}81 \\
8 \\
78 \\
19 \\
17 \\
42 \\
44 \\
47 \\
14 \\
25 \\
8 \\
8 \\
3 \\
6\end{array}$ \\
\hline
\end{tabular}

tasty and pleasant were well above $50 \mathrm{~mm}$ for each snack category indicating that all snacks were well liked (see Table 4).

\section{Provision of snacks}

Subjects were asked to eat a minimum number of snack units each day in order that at least $25 \%$ of their daily energy would be derived from the test snacks. This target was based on the results of analysis of data from $5 \mathrm{~d}$ food diary records, provided by seventy-five adults, carried out by Gatenby et al. (1995), and was consistent with the reported habitual intake of the snackers in the study. Gatenby et al. took the novel approach of asking subjects to define each

Table 3. Nutritional composition of snack units

\begin{tabular}{|c|c|c|c|c|c|c|c|c|c|}
\hline Snack category & Snack description & $\begin{array}{c}\text { Energy } \\
(\mathrm{kJ})\end{array}$ & \multicolumn{2}{|c|}{ Protein } & \multicolumn{2}{|c|}{ Carbohydrate } & \multicolumn{2}{|r|}{ Fat } & Wt (g) \\
\hline LF/SW & $\begin{array}{l}\text { Chocolate and orange topped sponge biscuit } \\
\text { Chocolate coated peanut butter bar } \\
\text { Apple and cinnamon muesli bar } \\
\text { Plain fudge } \\
\text { Category mean }\end{array}$ & $\begin{array}{l}381 \\
552 \\
469 \\
418 \\
455\end{array}$ & $\begin{array}{l}1 \cdot 2 \\
2 \cdot 2 \\
2 \cdot 1 \\
0 \cdot 5 \\
1 \cdot 5\end{array}$ & $\begin{array}{l}5 \cdot 3 \\
6 \cdot 8 \\
7 \cdot 3 \\
2 \cdot 0 \\
5 \cdot 4\end{array}$ & $\begin{array}{l}18 \cdot 2 \\
22 \cdot 6 \\
24 \cdot 1 \\
18 \cdot 9 \\
20 \cdot 9\end{array}$ & $\begin{array}{l}75 \cdot 0 \\
64 \cdot 2 \\
80 \cdot 5 \\
70 \cdot 9 \\
72 \cdot 6\end{array}$ & $\begin{array}{l}2 \cdot 0 \\
4 \cdot 3 \\
1 \cdot 6 \\
3 \cdot 0 \\
2 \cdot 7\end{array}$ & $\begin{array}{l}19 \cdot 7 \\
29 \cdot 0 \\
12 \cdot 5 \\
27 \cdot 0 \\
22 \cdot 1\end{array}$ & $\begin{array}{l}25 \cdot 0 \\
33 \cdot 0 \\
33 \cdot 0 \\
25 \cdot 0 \\
29 \cdot 0\end{array}$ \\
\hline LF/NSW & $\begin{array}{l}\text { Bacon hoops } \\
\text { Pizza pieces } \\
\text { Barbecue waffles } \\
\text { Category mean }\end{array}$ & $\begin{array}{l}481 \\
385 \\
385 \\
417\end{array}$ & $\begin{array}{l}1 \cdot 7 \\
1 \cdot 5 \\
1 \cdot 8 \\
1 \cdot 7\end{array}$ & $\begin{array}{l}5 \cdot 9 \\
6 \cdot 5 \\
7 \cdot 8 \\
6 \cdot 7\end{array}$ & $\begin{array}{l}20 \cdot 1 \\
22 \cdot 1 \\
20 \cdot 8 \\
21 \cdot 0\end{array}$ & $\begin{array}{l}65 \cdot 5 \\
90 \cdot 1 \\
84 \cdot 9 \\
80 \cdot 2\end{array}$ & $\begin{array}{l}3 \cdot 6 \\
0 \cdot 3 \\
0 \cdot 7 \\
1.5\end{array}$ & $\begin{array}{r}28 \cdot 2 \\
2 \cdot 9 \\
6 \cdot 8 \\
12 \cdot 6\end{array}$ & $\begin{array}{l}30 \cdot 0 \\
27 \cdot 0 \\
27 \cdot 0 \\
28 \cdot 0\end{array}$ \\
\hline
\end{tabular}

LF, low-fat; SW, sweet; HF, high-fat; NSW, non-sweet. 
Table 4. Pre-study taste-test results

(Mean values with their standard deviations for thirty-six subjects)

\begin{tabular}{|c|c|c|c|c|c|c|c|c|c|c|c|c|c|c|}
\hline \multirow{2}{*}{$\begin{array}{l}\text { Questions ... } \\
\text { Snack category }\end{array}$} & \multicolumn{2}{|c|}{ Sweet } & \multicolumn{2}{|c|}{ Savoury } & \multicolumn{2}{|c|}{ Tasty } & \multicolumn{2}{|c|}{ Pleasant } & \multicolumn{2}{|c|}{$\begin{array}{l}\text { Predicted } \\
\text { filling }\end{array}$} & \multicolumn{2}{|c|}{$\begin{array}{l}\text { Predicted } \\
\text { satisfying }\end{array}$} & \multicolumn{2}{|c|}{$\begin{array}{l}\text { Prospective } \\
\text { consumption }\end{array}$} \\
\hline & Mean & $\mathrm{SD}$ & Mean & $\mathrm{SD}$ & Mean & SD & Mean & $\mathrm{SD}$ & Mean & SD & Mean & SD & Mean & SD \\
\hline HF/SW & 75 & 13 & 11 & 10 & 73 & 12 & 74 & 14 & 48 & 18 & 61 & 17 & 60 & 19 \\
\hline LF/NSW & 17 & 15 & 77 & 16 & 71 & 15 & 69 & 16 & 41 & 20 & 52 & 16 & 62 & 21 \\
\hline HF/NSW & 17 & 14 & 75 & 17 & 73 & 14 & 75 & 12 & 52 & 19 & 63 & 17 & 68 & 18 \\
\hline
\end{tabular}

LF, low-fat; SW, sweet; HF, high-fat; NSW, non-sweet.

eating episode as a 'meal' or 'snack' and found that, on average, 'meals' provided $75 \%$ and 'snacks' $25 \%$ of total daily EI. The daily EI of each subject was estimated by calculating their estimated energy expenditure (EE). Baseline food diary data, analysed at the end of the study, later confirmed these estimates. Assuming that body weight is stable, EE should be equal to EI. The estimated EE of each subject was derived from their estimated BMR and their reported physical activity level (PAL; estimated $\mathrm{EE}=$ $\mathrm{BMR} \times \mathrm{PAL}) . \mathrm{A}$ PAL of 1.6 was used for the majority of subjects and a value of 1.75 was used for particularly active individuals. These values are based on the review by Black et al. (1996). BMR (kJ/24h) was estimated for each subject using the appropriate Schofield equation (Schofield et al. 1985). For each individual, $25 \%$ of their estimated EI $(0 \cdot 25 \times$ estimated EE) was calculated and 'translated' into snack units by dividing by 418 (the approximate $\mathrm{kJ} /$ snack unit) and rounding to the nearest whole snack. Subjects were asked to try to consume their own personal minimum number of snacks every day and as many additional snacks as they liked.

Subjects were provided with enough snacks each week to eat double this minimum amount and were instructed that they should return to the Human Appetite Research Unit at any time during the week for more snacks if necessary. The snacks were supplied to the subjects in anonymous wrappers (i.e. brand and manufacture name was not indicated) and packed in large sports bags for the subjects' convenience. In the sweet-snack conditions where there were four available snacks, subjects were provided with their three most preferred snacks only. Thus during each snack condition subjects were provided with a choice of three snacks.

\section{Study measures and procedure}

The study was carried out during the period from the beginning of June until the end of November 1996. It was split into four experimental phases and the subjects run as two staggered cohorts of twenty. Throughout the study the subjects were required to visit the Human Appetite Research Unit on at least twenty occasions and so the study procedure was manipulated so that each individual's visits would always fall on the same day of the week for their convenience. This day was chosen by the subjects. Each phase of the study was run according to a standard procedure. Different measures were made on day 0, days 1-6, day 7 , days 8-13, day 14 , days $15-20$ and day 21 , not all of which are reported here. Measures not reported here, including subjective ratings of hunger motivation, appetite and mood completed using the Leeds Electronic Appetite Rating System (Delargy et al. 1996), will be reported elsewhere.

\section{Snacking records}

On every day of each experimental phase (days 1-21) subjects were required to fill in a snacking record. This inventory was designed in a grid-like fashion, with snacktype across the top and time of day down the left hand side (split into the same intervals as in the food diary described below). This enabled the subject to enter the quantity of each snack consumed and at what time of the day. All records were marked with the appropriate date for completion. Subjects returned their snack records to the Human Appetite Research Unit at the end of each week together with snack wrappers (from consumed snacks) and all uneaten snacks. This was done both to verify the snack records and to aid compliance.

\section{Food diary records}

Food diary records were kept for $3 \mathrm{~d}$ (two weekdays and one weekend day) both before the start of the study (baseline intakes) and during each experimental phase (between days 15 and 20). The food diary used in this study was specially designed for the purposes of the study. At the front of the diary, detailed information on how to record food and drink consumed using common household measures was provided. The diary itself was split up into various time periods across the day for several reasons. First, specifically prompting subjects to record intake between meals etc. may help to reduce subjects' forgetting to record food and drink consumed between meals. Second, subjects were required to define their eating episodes as meals or snacks. Third, to facilitate analysis of the profile of eating across the day. The diary also provided a space for subjects to record their activity level throughout the day and to indicate whether they had felt well. This information was useful in order to ascertain whether anything particularly unusual had occurred during the day that might have had an impact on any subject's appetite and food intake (e.g. if the subject had been ill). When completing the food diary records, subjects were instructed to record everything they ate or drank apart from any snacks that had been provided by the study. These were to be recorded using the snacking records described above. Food diary records were returned to the Human Appetite Research Unit as soon as possible after completion when they were reviewed by the study dietitian. 


\section{Body weight measurement}

Body weight was measured on days $0,7,14$ and 21 of each experimental phase. Subjects were weighed on a Salter digital weighing balance, accurate to $0.1 \mathrm{~kg}$. They were weighed at the same time each day (early morning, before breakfast), in light indoor clothing (with shoes removed) and after voiding their bladder.

\section{Statistical analysis}

All data were analysed using the SAS System (version 6.10). The repeated-measures ANOVA were conducted using the GLM procedure for analysing the data in univariate mode. This allowed all available data to be included in the analysis. Post-hoc tests were conducted using Tukey's multiple comparison method.

\section{Snack intakes}

Snack intake data (from both the whole of each $21 \mathrm{~d}$ exposure period and the $3 \mathrm{~d}$ recording periods when subjects were completing food diary records) were analysed by three-way analyses of variance (ANOVA). Snack taste (SW or NSW) and snack macronutrient (LF or HF) were the repeated-measures factors in the analysis and subject sex (male or female) was an independent factor. Snack data from the $3 \mathrm{~d}$ records were excluded from the analysis if the corresponding diary data were missing.

\section{Intakes from food diary records}

All food diary data collected during the study were analysed using the dietary analysis package COMP-EAT (version 4.0; Lifeline Nutrition Services, London, UK), a computerized version of the UK Food Tables (Holland et al. 1991), with the addition of specific food items using the manufacturer's nutritional information, where necessary (n 538). Energy and macronutrient intakes from food consumed in addition to the study snacks ( $3 \mathrm{~d}$ record data) were analysed by three-way ANOVA as already described for the snackintake data. Diary data were excluded from the analysis if the corresponding snack intakes were missing.

\section{Total intakes during the 3 d records (snack plus diary intakes)}

These data were derived by adding intakes from the snacking records to those from the corresponding food diary records. If a subject did not provide both sets of data for a particular day or days (e.g. if the subject filled in the snacking record but not the food diary record) then the subject's data for that (those) day(s) were excluded from the analysis. These data were analysed by threeway ANOVA as already described. They were also analysed in conjunction with intake data from the baseline food diaries, (a) to determine how exposure to particular snacks might affect daily EI and (b) to determine any effect of order of completing the food diaries on the amount of intake recorded, by one-way repeated-measures ANOVA.

\section{Body weight data}

Body weights measured at the beginning (day 0 of phase 1) and end (day 21 of phase 4) of the study were compared using the Student's $t$ test for paired comparisons.

\section{Ethical considerations}

The study was approved by the Ethics Committee of the School of Psychology, University of Leeds, Leeds. The informed consent of each subject was obtained in written form. Subjects were given a small honorarium to compensate for their time.

\section{Results}

\section{Baseline daily energy and macronutrient intakes}

The mean daily energy and macronutrient intakes ( $\mathrm{g}$ and percentage of energy) of the subjects, assessed by food diary recordings made before the start of the study, are shown in Table 5. Male subjects reported consuming an average of $12 \cdot 28 \mathrm{MJ} / \mathrm{d}$, an intake which closely matched their estimated EI $(12 \cdot 52 \mathrm{MJ} / \mathrm{d})$. For female subjects the reported EI $(9.95 \mathrm{MJ} / \mathrm{d})$ was found to be a little higher than their estimated EI $(9 \cdot 14 \mathrm{MJ} / \mathrm{d})$. The data from the subject group as a whole (and from the separate sexes) indicated that subjects consumed around $37 \%$ of their total daily EI as fat, $43 \%$ as carbohydrate and $13 \%$ as protein.

The mean daily EI of the subjects participating in this study are somewhat higher than the corresponding data reported by Gregory et al. 1990, in which males aged between 16-24 and 25-34 years were reported to consume $10 \cdot 29$ and $10 \cdot 21 \mathrm{MJ} / \mathrm{d}$ respectively. Females in the same age groups were reported to consume $7 \cdot 1$ and $7 \cdot 0 \mathrm{MJ} / \mathrm{d}$ respectively. The macronutrient composition of the diet consumed

Table 5. Baseline daily energy $(\mathrm{MJ} / \mathrm{d})$ and macronutrient intakes $(\mathrm{g} / \mathrm{d}$ and percentage of energy/d) assessed by $3 \mathrm{~d}$ food-diary records made before the start of the study

(Mean values with their standard deviations for thirty-six subjects)




by the males and females in the present study is, however, almost identical to that reported by Gregory et al. (1990).

\section{Snack intakes}

Snack intakes during days 1-21 of snack exposure. Profiles of energy $(\mathrm{kJ})$ and fat $(\mathrm{g})$ consumed from the different snacks across the $21 \mathrm{~d}$ exposure period are shown in Fig. 1 ( $a$ and b) respectively. As can be seen from the figures, intakes remained fairly stable over time. On every day of snack exposure (or consumption), subjects consumed most energy from the HF/SW snacks and least energy from the LF/NSW snacks. Additionally, more energy was consumed from the LF/SW snacks than from the HF/NSW snacks. As would be expected, subjects consumed more fat from the two HF snack categories than from the two LF snack categories. In addition, subjects consumed more fat from the HF/SW snacks than from the HF/NSW snacks. These data are summarised in Table 6 which shows the average daily energy $(\mathrm{kJ})$ and macronutrients ( $\mathrm{g}$ and percentage of energy) consumed from the different snacks during these periods. Analysis of these average intakes over the whole exposure period (see also Table 6 for main results) shows that subjects consumed more energy from the SW snacks than from the NSW snacks, and more of all macronutrients (in terms of weight) from the SW snacks than from the NSW snacks. In addition, subjects consumed more energy from the HF snacks than from the corresponding LF snacks (i.e. $\mathrm{HF} / \mathrm{SW}>\mathrm{LF} / \mathrm{SW}$ and $\mathrm{HF} / \mathrm{NSW}>\mathrm{LF} / \mathrm{NSW}$ ) and this effect was greatest when the NSW snacks were consumed (snack taste $\times$ snack macronutrient interaction; see Table 6). Subjects consumed more fat and protein, and less carbohydrate, when they were provided with the HF snacks than when they were provided with the corresponding LF snacks and this effect on protein and carbohydrate intake was greatest when the SW snacks had been provided (snack taste $\times$ snack macronutrient interactions; see Table 6). Male subjects consumed significantly more energy, and
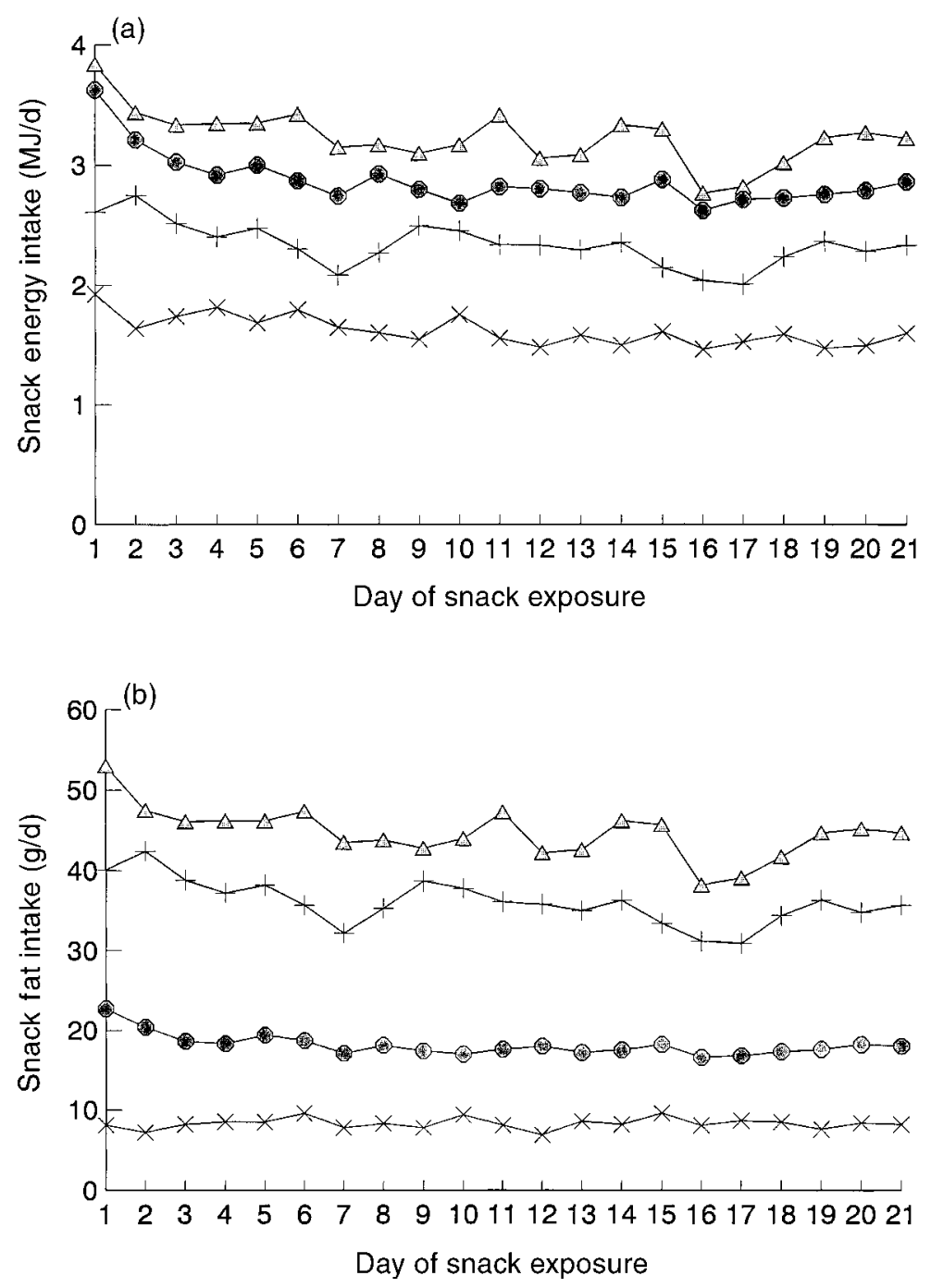

Fig. 1. Mean daily snack energy (a) and fat (b) intakes of eighteen male and eighteen female subjects determined snacking records on each of the $21 \mathrm{~d}$ of snack exposure. Snack categories were low-fat/sweet $(\odot)$, high-fat/sweet $(\Delta)$, low-fat/non-sweet $(x)$ and high-fat/non-sweet $(+)$. 

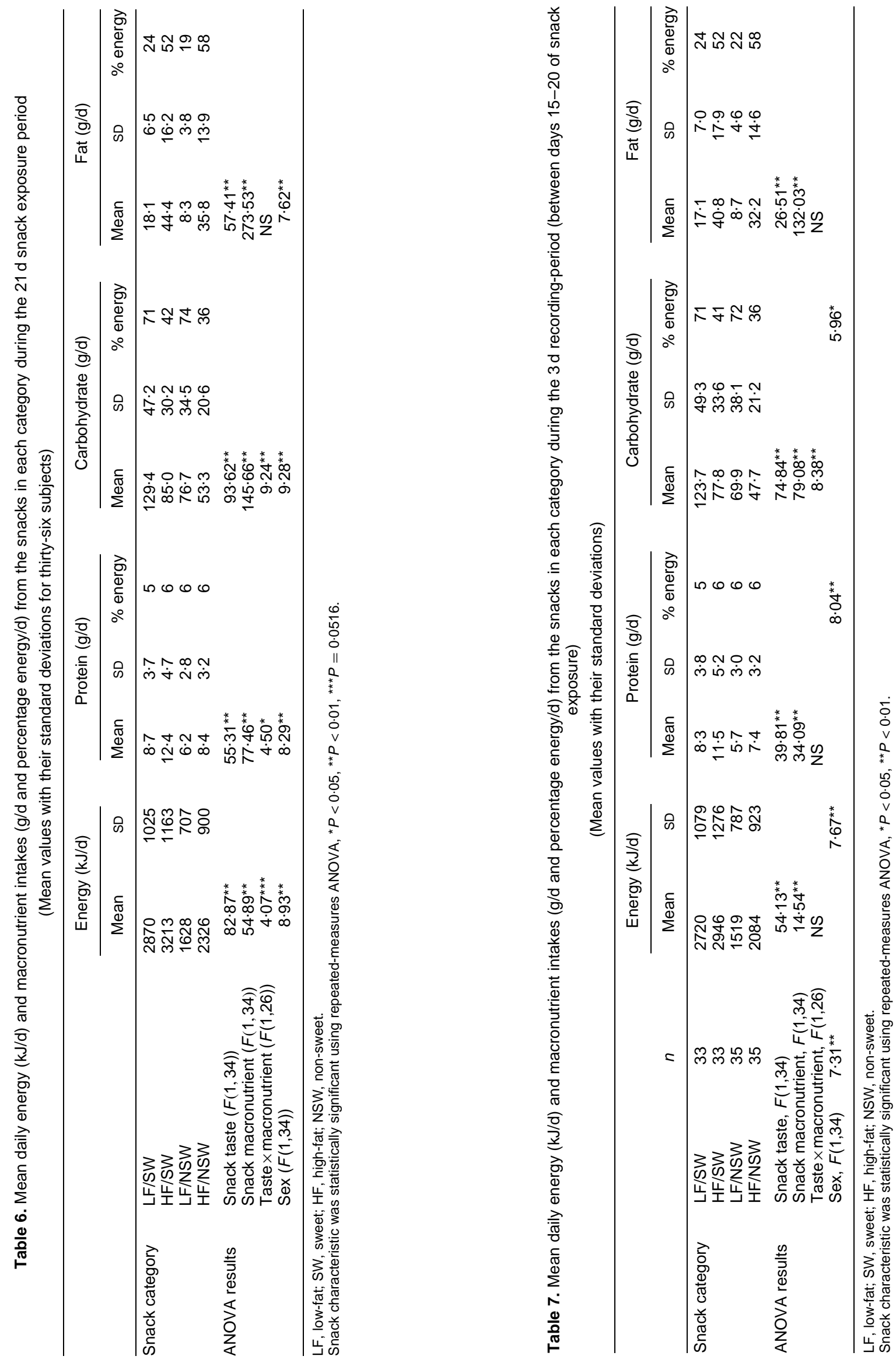
consequently more of all macronutrients, than female subjects and this effect of subject sex on fat and carbohydrate intake was greatest when the HF snacks were consumed (snack macronutrient $\times$ sex interactions, smallest $F(1,34) 4 \cdot 26, P<0 \cdot 05)$.

Snack intakes during the $3 d$ records. These data are shown in Table 7 and compare well with the intakes shown in Fig. 1( $a$ and b) and Table 6. The main results of the analysis carried out on these data can also be seen in Table 7. The results are not described here since they are broadly representative of the results of analysis of the whole $21 \mathrm{~d}$ exposure period (see above).

\section{Intakes from food diary records during snack exposure}

The mean of subjects' average daily energy (MJ) and macronutrient ( $\mathrm{g}$ and percentage of energy) intakes from their own foods, over the $3 \mathrm{~d}$ of recording on each snack condition, together with the main results of analysis carried out on these data are shown in Table 8. Subjects consumed more energy, fat and carbohydrate, but no more protein or alcohol, from their own foods when they were exposed to the two NSW snack conditions than when they were exposed to the two SW snack conditions, thus compensating for the lower consumption of energy from the NSW snacks. Macronutrient intakes expressed as percentage of energy intake, however, did not differ across snack conditions. Overall, male subjects consumed more energy, fat, carbohydrate and protein but no more alcohol than female subjects.

\section{Total intakes during the $3 d$ records (snack plus diary intakes)}

Total (snack plus diary) daily energy (MJ) and macronutrient ( $g$ and percentage of energy) intakes averaged across the $3 \mathrm{~d}$ of recording on each snack condition, together with the main results of analysis carried out on these data, are shown in Table 9. Total daily EI was highest when the HF snacks were being consumed. On average, subjects consumed an extra $364 \mathrm{~kJ} / \mathrm{d}$ when the HF snacks were consumed compared with when the LF snacks were consumed. This effect of snack macronutrient on EI was not statistically significant but significant effects on fat and carbohydrate intakes were apparent (see Table 9).

Fat intakes (both $g$ and percentage of energy) were significantly increased when subjects consumed the HF snacks compared with when they consumed the LF snacks, whilst carbohydrate intakes (both $g$ and percentage of energy) were significantly reduced. Carbohydrate intake was also found to be dependent on the sweetness of the snacks (ANOVA revealed a significant main effect of snack taste in addition to the main effect of snack macronutrient). Hence, subjects consumed more carbohydrate (both $\mathrm{g}$ and percentage of energy) when consuming the SW snacks than when consuming the corresponding NSW snacks and the effect of carbohydrate was greatest when the snacks were low-fat (significant snack taste $\times$ snack macronutrient interaction; see Table 9). Protein and alcohol intakes ( $g$ and percentage of energy) remained relatively stable and were not significantly different across the four snack conditions.
Across all snack conditions, male subjects consumed significantly more energy, protein, fat and carbohydrate, but no more alcohol, than female subjects.

\section{Comparison of total daily intakes during snack exposure with baseline intakes}

There were no significant differences between baseline daily EI and total daily EI during exposure to any of the four categories of snack $(F(4,126) 1 \cdot 02$, NS). Similarly, there were no significant differences in protein $(\mathrm{g}: F(4,126)$ $2 \cdot 28$, NS) or alcohol $(\mathrm{g}: F(4,126) 1 \cdot 17, \mathrm{NS})$ intakes at these times. Significant differences in fat $(\mathrm{g}: F(4,126) 10 \cdot 22$, $P<0.01$; percentage of energy: $F(4,126) 23.63, P<0.01)$ and carbohydrate (g: $F(4,126) 7 \cdot 35, P<0 \cdot 01$; percentage of energy: $F(4,126) 22 \cdot 60, P<0 \cdot 01)$ intakes were, however, apparent.

Consumption of the HF/NSW snacks significantly $(P<0 \cdot 01)$ increased the absolute intake of fat, from $107 \cdot 9$ to $122.6 \mathrm{~g}$, whilst consumption of snacks in both $\mathrm{HF}$ categories significantly $(P<0 \cdot 01)$ increased the percentage of energy consumed as fat from 37 to $41 \%$. Consumption of the LF/SW snacks, however, significantly $(P<0.05)$ reduced the percentage of energy consumed as fat to $33 \%$ (see Table 5 (all subjects) and Table 9). Consumption of the LF/NSW snacks also reduced the percentage of energy consumed as fat (from 37 to $34 \%$ ) but this reduction was not statistically significant. With respect to carbohydrate intakes, consumption of the LF/SW snacks significantly $(P<0.05)$ increased the absolute intake of carbohydrate from 302.5 to $335.7 \mathrm{~g}$, whilst consumption of snacks in both LF categories significantly increased the percentage of energy consumed as carbohydrate from 43 to $49 \%$ (LF/ $\mathrm{SW}, P<0.01)$ and $45 \%$ (LF/NSW, $P<0.05)$. Consumption of the HF/NSW snacks, however, significantly $(P<0.05)$ reduced the percentage of energy consumed as carbohydrate to $40 \%$ (see Table 5 (all subjects) and Table 9). Consumption of the HF/SW snacks also reduced the percentage of energy consumed as carbohydrate (from 43 to $41 \%$ ), but this reduction was not statistically significant.

It is important to note that the data described here were not affected by the order of completion of the $3 \mathrm{~d}$ food diary records $(F(4,126) 1 \cdot 59$, NS) which were made five times during the study; at baseline and during exposure to each of the four snack types (providing 73-81\% of total daily EI data during snack exposure).

\section{Body weight data}

The mean body weight of the whole subject group ( $n$ 36) did not change significantly during the whole study period $(t$ $1 \cdot 83, P=0 \cdot 076$, df 35$)$. Similarly male subjects showed no change in body weight $(t 0.64, P=0.53$, df 17). Female subjects, however, showed a small rise in body weight $(+0.71 \mathrm{~kg})$ which just failed to reach significance $(t 2 \cdot 05$, $P=0 \cdot 056$, df 17).

\section{Discussion}

Subjects selectively consumed different amounts of the four snack types. More energy was consumed from the SW 

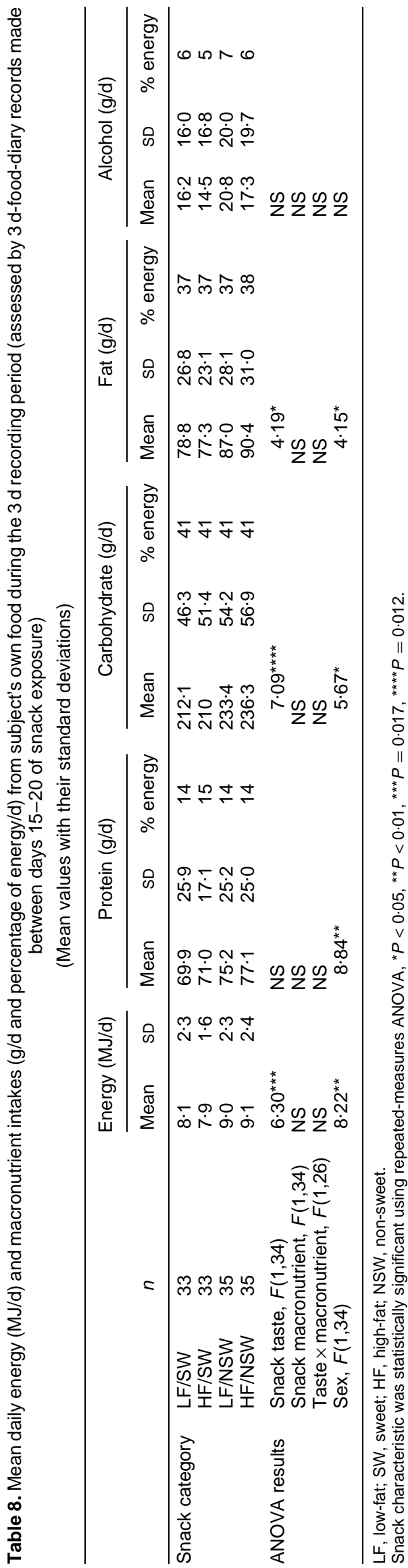

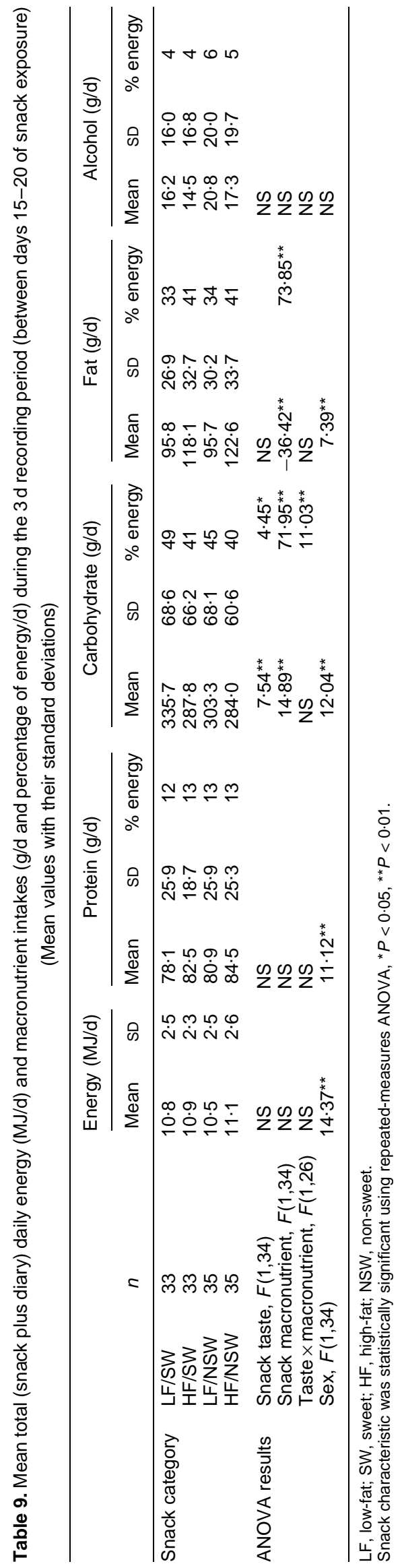


snacks than from the NSW snacks with most energy being consumed from the HF/SW snacks and least energy from the LF/NSW snacks. These intakes are likely to reflect natural preferences although we recognize that subjects would probably have consumed a mixture of SW and NSW snacks had they been allowed.

Subjects found no difficulty in eating the required snack intake (25\% of usual daily EI) when the SW snacks were consumed (LF/SW, $25 \% \mathrm{EI}$; HF/SW, $27 \% \mathrm{EI}$ ) but did have some difficulty consuming the NSW snacks (LF/NSW, $14 \%$ EI; HF/NSW, $19 \%$ EI). Part of the rationale of the study was, however, to determine how many snacks (of each type) subjects would choose to consume, given that the snacks were rated equally pleasant at the start. Forcing people to eat specific amounts of the snacks, against their will, would have interfered with natural food choice and appetite control processes. Hence, despite the uneven snack consumption across categories, a successful dietary intervention, which remained fairly stable across each 3-week period, was made and this gives the opportunity to examine the impact of snacking on energy balance. This is in line with the study of van het Hof et al. (1997) who showed that it is feasible to conduct an experimental manipulation of the fat content of supplied products in a relatively free-living and therefore realistic situation.

The study by van het Hof et al. (1997) provides the first published data of a randomized placebo-controlled trial in healthy subjects, of the effects of ad libitum consumption of reduced-fat products for an extended period of time, as part of the normal diet. Longer-term studies of this type will be very important in advancing the understanding of the role of reduced-fat products in the diet. Subjects participating in the study were required to eat freely from either full-fat or corresponding reduced-fat foods (most of which could be obtained free of cost from a special shop installed at each research centre) for a period of 6 months. The aim of the study was to obtain a $50 \%$ difference in fat intake between the two treatment groups. The researchers estimated that this could be achieved provided that the reduced-fat products derived $50 \%$ less fat (a difference of around $17 \cdot 5 \mathrm{~g} / \mathrm{d}$ ) than the full-fat products and if the control group consumed $70 \%$ of their total fat intake from the supplied products. Subjects in the reduced-fat group were therefore required to consume at least a minimum amount of the reduced-fat products. The results of the study showed that the reducedfat group consumed an average of $46 \%$ less fat from the supplied products than did the full-fat group. In addition, the consumption of these supplied products did not decline over time. The effect of this dietary intervention on daily energy and macronutrient intakes was measured by $3 \mathrm{~d}$ food diary records (as in the present study) after 2 to 4 weeks, at 3 months and at the end of the study. The main outcome was that subjects who consumed the reduced-fat foods reduced their intake of fat but not energy (as in the present study), and had no significant changes in body weight over the study. In contrast, subjects who consumed the full-fat products increased their fat and energy intakes significantly and gained weight (Westerterp et al. 1996).

The encouragement to eat freely from the supplied foods in the present study (which were provided free and in generous quantities) did not lead to daily overconsumption when compared with pre-study EI. Hence, in these particular subjects (normal-weight, habitual snackers), appreciable snack consumption (up to nine snacks/d) did not lead to excessively high total daily EI. It is possible that these data could have been affected by the tedium of keeping $3 \mathrm{~d}$ food diary records five times during the study. Analysis, however, showed that this was not the case (no main effect of order of food diary record completion, $F(4,126) 1.59$, NS). Hence, there was no decrease in recorded EI as a function of study duration (which could have masked any overconsumption induced by the snacks). Although female subjects did show a small rise in body weight $(+0.71 \mathrm{~kg})$ over the whole study period $(147 \mathrm{~d})$, which just failed to reach significance $(t 2 \cdot 05, P=0 \cdot 056$, degrees of freedom 17), male subjects showed no change in body weight.

The low consumption of the LF/NSW snacks raises an interesting issue concerning sensory evaluation of foods and their actual consumption. Before the start of the study, great care was taken to ensure that preferences for all the snack categories were equivalent. However, once subjects began eating the snacks, the rather low EI from the LF/NSW snacks indicated that the snacks in this category were actually less preferred in comparison to those in the other categories. The low consumption of these snacks did however, provide an opportunity for the expression of good compensation from the rest of the eating episodes. Despite the fact that subjects consumed significantly more energy from the SW snacks than from the NSW snacks (Fig. 1(a), Tables 6 and 7), it is clear from Table 8 that subjects compensated for this by decreasing their intake at other eating episodes when consuming the SW snacks. Compensation for the higher energy consumed from the HF snacks was less efficient and hence total intakes were highest when the HF snacks were consumed. Although this effect on total EI was non-significant, the $P$ value here is determined by individual variation and by $n$, resulting in relatively low statistical power. The increased EI on the HF snacks compared with that on the LF snacks amounted to an average of $364 \mathrm{~kJ} / \mathrm{d}$. If this difference were maintained over the course of 1 year it would have the potential to lead to a body weight difference of between 3.6 and $4.1 \mathrm{~kg}$ for subjects consuming either the HF or LF snacks. The small effect of snack macronutrient on daily energy balance would not, therefore, be inconsequential. However, in general, the particular subjects used in this study showed a good capacity to regulate total daily EI in the face of varying intakes from the different snacks.

The clearest and most significant effect of snack consumption was on daily fat and carbohydrate intakes. With appreciable consumption of the HF snacks, daily fat intake was approximately $120 \mathrm{~g} / \mathrm{d}$ which amounted to $41 \%$ of total daily energy. In contrast, the LF snacks reduced daily fat intake to $96 \mathrm{~g} / \mathrm{d}$ or $33.5 \%$ total daily energy. It is important to note that unrestricted consumption of the LF snacks caused fat intakes to approach the value prescribed in dietary guidelines (i.e. less than $35 \%$ total food energy) without increasing total daily EI. This means that the LF snacks did not simply add on to normal intake and, therefore, 'dilute' percentage fat intake by simply adding in extra non-fat (carbohydrate) energy. Consequently this encouragement to eat freely from LF snacks appears to be an 
effective strategy to optimize fat consumption, at least in habitual snackers.

It should be pointed out that this dietary manipulation did not threaten the nutrient benefits of dietary fat. Subjects were still consuming over $90 \mathrm{~g}$ of fat/d on average and would, therefore, be likely to be obtaining an ample supply of polyunsaturated fatty acids, fat-soluble vitamins (e.g. vitamin E) and antioxidants (e.g. $\beta$-carotene). An average intake of $33-34 \%$ of total daily EI is still supplying a more than adequate amount of dietary fat. In conclusion then, the present data suggest that consumption of LF snacks (in a relatively free-living situation) can lower daily energy and fat intakes and help to achieve dietary targets for fat consumption (at least in normal-weight habitual snackers) without threatening the nutrient benefits of dietary fat.

\section{Acknowledgements}

This work was conducted as part of the MAFF AGRO FOOD LINK PROJECT (LINK AFQ 26M). It was sponsored by the Ministry of Agriculture, Fisheries and Food and by a consortium of industrial partners (Cadbury (UK) Ltd., Nestle Ltd., The Sugar Bureau, Unilever Research Laboratories, United Biscuits (UK) Ltd.). The authors wish to thank Derrick Joanes (Department of Statistics, University of Leeds) for statistical advice.

\section{References}

Basdevant A, Craplet C \& Guy-Grand B (1993) Snacking patterns in obese French women. Appetite 21, 17-23.

Beaudoin R \& Mayer J (1953) Food intakes of obese and nonobese women. Journal of the American Dietetic Association 29, 29-33.

Bellisle F, McDevitt R \& Prentice AM (1997) Meal frequency and energy balance. British Journal of Nutrition 77, Suppl. 1, 57S$70 \mathrm{~S}$.

Black AE, Coward WA, Cole TJ \& Prentice AM (1996) Human energy expenditure in affluent societies: an analysis of 574 doubly-labelled water measurements. European Journal of Clinical Nutrition 50, 72-92.

Blundell JE, Burley VJ, Cotton JR \& Lawton CL (1993) Dietary fat and the control of energy intake: evaluating the effects of fat on meal size and post-meal satiety. American Journal of Clinical Nutrition 57, Suppl., 772S-778S.

Blundell JE \& Hill AJ (1988) Do serotoninergic drugs decrease energy intake by reducing fat or carbohydrate intake? Effect of $d$-fenfluramine with supplemented weight-increasing diets. Pharmacology Biochemistry and Behaviour 31, 773-778.

Bolton-Smith C \& Woodward M (1994) Dietary composition and fat to sugar ratios in relation to obesity. International Journal of Obesity 18, 820-828.

Burley VJ, Cotton JR, Weststrate JA \& Blundell JE (1993) Effect on appetite of replacing natural fat with sucrose polyester in meals or snacks across one whole day. In Obesity in Europe, pp. 213-219 [H Ditschuneit, FA Gries, H Hauner, V Schusdziarra and JG Wechsler, editors]. London: John Libbey and Company Ltd.

Delargy HJ, Lawton CL, Smith FC, King NA \& Blundell JE (1996) Electronic Appetite Rating System (EARS): Validation of continuous automated monitoring of motivation to eat. International Journal of Obesity 20, Suppl. 4, 104S.

Dreon DM, Frey-Hewitt B, Ellsworth N, Williams PT, Terry RB \& Wood PD (1988) Dietary fat: carbohydrate ratio and obesity in middle aged men. American Journal of Clinical Nutrition 47, 995-1000.

Drewnowski A, Kurth C, Holden-Wiltse J \& Saari J (1992) Food preferences in human obesity: carbohydrates versus fats. Appetite 18, 207-221.

Emmett PM \& Heaton KW (1995) Is extrinsic sugar a vehicle for dietary fat? Lancet 345, 1537-1540.

Fabry P, Fodor J, Hejl Z, Braun T \& Zvolankova K (1964) The frequency of meals. Its relation to overweight, hypercholesterolaemia and decreased glucose-tolerance. Lancet ii, 614-615.

Gatenby SJ, Anderson AO, Walker AD, Southon S \& Mela DJ (1995) 'Meals' and 'snacks': implications for eating patterns in adults. Appetite 24, 292.

Glinsmann WH, Irausquin H \& Park YK (1986) Evaluation of health aspects of sugars contained in carbohydrate sweeteners. Journal of Nutrition 116, Suppl., 11S.

Golay A \& Bobbioni E (1997) The role of dietary fat in obesity. International Journal of Obesity 21, Suppl. 3, 2S-11S.

Green SM \& Burley VJ (1996) The effects of snacking on energy intake and body weight. British Nutrition Foundation Nutrition Bulletin 21, 103-108.

Green SM, Burley VJ \& Blundell JE (1994) Effect of fat- and sucrose-containing foods on the size of eating episodes and energy intake in lean males: potential for causing overconsumption. European Journal of Clinical Nutrition 48, 547-555.

Gregory J, Foster K, Tyler H \& Wiseman M (1990) The Dietary and Nutritional Survey of British Adults. London: HM Stationery Office.

Health of the Nation (1992) A strategy for health in England. London: HM Stationery Office.

Holland B, Welch AA, Unwin ID, Buss DH, Paul AA \& Southgate DAT (1991) McCance and Widdowson's The Composition of Food, 5th ed. Cambridge: The Royal Society of Chemistry and the Ministry of Agriculture Fisheries and Food.

Kanarek RB \& Hirsch E (1977) Dietary-induced overeating in experimental animals. Federation Proceedings 36, 154-158.

Kuczmarski RJ, Flegel KM, Campbell SM \& Johnson CL (1994) Increasing prevalence of overweight among US adults: the national health and nutrition examination surveys 1960-1991. Journal of the American Medical Association 272, 205-211.

Lawton CL, Burley VJ, Wales JK \& Blundell JE (1993) Dietary fat and appetite control in obese subjects: weak effects on satiation and satiety. International Journal of Obesity 17, 409-416.

Macdiarmid JI, Cade JE \& Blundell JE (1995) Extrinsic sugar as a vehicle for dietary fat. Lancet 346, 696-697.

Mela DJ \& Rogers PJ (1993) 'Snack Foods', Overeating and Obesity: Relationships with food composition, palatability and eating behaviour. British Food Journal 95, 13-19.

Metzner HL, Lamphiear DE, Wheeler NC \& Larkin FA (1977) The relationship between frequency of eating and adiposity in adult men and women in the Tecumseh Community Health Study. American Journal of Clinical Nutrition 30, $712-715$.

Millar WC, Lindeman AK, Wallace J \& Niederpruem H (1990) Diet composition, energy intake and exercise in relation to body fat in men and women. American Journal of Clinical Nutrition 52, 426-430.

National Research Council, National Academy of Science (1989) Diet and Health. Washington DC: National Academy Press.

Prentice AM \& Jebb SA (1995) Obesity in Britain: gluttony or sloth? British Medical Journal 311, 437-439.

Prescott-Clarke P, Primatesta P, Bost L, Dong W, Hedges B, Prior G, Purdon S \& di Salvo P (1997) Health Survey for England 1995. London: HM Stationery Office.

Romieu I, Willet WC, Stampfer MJ, Colditz GA, Sampson L, Rosner B, Hennekens CH \& Speizer FE (1988) Energy intake 
and other determinants of relative weight. American Journal of Clinical Nutrition 47, 406-412.

Schofield W, Schofield C \& James WPT (1985) Basal metabolic rate: review and prediction, together with an annotated bibliography of source material. Human Nutrition Clinical Nutrition 39C, Suppl., 1S-96S.

Sclafani A \& Springer D (1976) Dietary obesity in normal adult rats: similarities to hypothalamic and human obesity syndromes. Physiology and Behaviour 17, 461-471.

Stunkard AJ \& Messick S (1985) The three-factor eating questionnaire to measure dietary restraint, disinhibition and hunger. Journal of Psychosomatic Research 29, 71-83.

Tremblay A, Plourde G, Depres J-P \& Bouchard C (1989) Impact of dietary fat content and fat oxidation on energy intake in humans. American Journal of Clinical Nutrition 49, 799-805.

van het Hof KH, Weststrate JA, van den Berg H, Velthuis-te Wierik EJM, de Graaf C, Zimmermanns NJH, Westerterp KR, Wersterterp-Plantenga MS, Verboerket-van de Venne WPHG (1997) A long-term study on the effect of spontaneous consumption of reduced fat products as part of a normal diet on indicators of health. International Journal of Food Science and Nutrition 48, 19-29.

Westerterp KR, Verboeket-van de Venne WPHG, WesterterpPlantenga MS, Velthuis-te Wierik EJM, de Graaf C \& Weststrate JA (1996) Dietary fat and body fat: an intervention study. International Journal of Obesity 20, 1022-1026. 